\title{
The Need to Look Beyond the Production and Provision of Relief Seed: Experiences from Southern Sudan
}

\author{
Richard B. Jones \\ Intl. Crops Research \\ Institute for the Semi- \\ arid Tropics (ICRISAT)
Catherine Longley ODI/ICRISAT

\author{
Paula Bramel \\ ICRISAT
}

Free distribution of seeds in selected areas of southern Sudan has been widespread as a way of increasing food security. Field research in areas targeted for seed relief found that farmer seed systems continue to meet the crop and varietal needs of farmers even following the 1998 famine. Donor investments in seed multiplication of improved sorghum have not been sustained due to a lack of effective demand for the improved seed beyond that created by the relief agencies. The article argues that rather than imposing outside solutions, whether through seed provisioning or seed production enterprises, greater attention needs to be given to building on the strengths of existing farmer systems and designing interventions to alleviate the weaknesses. The case is made to support dynamically the process of farmer experimentation through the informed introduction of new crops and varieties that can potentially reinforce the strength and diversity of local cropping systems.

Keywords: seed, sorghum, relief, adapted, germplasm, availability, access.

\section{Introduction}

The civil war in Sudan is one of the longest running wars in Africa and in the world. The country has only known a decade of peace since independence in 1956, and the latest conflict has lasted since 1983 with the breakdown of the Addis Ababa Agreement between southern rebels and a succession of northern governments. The extent and scale of the disaster has led to unprecedented levels of humanitarian assistance, and criticism that the humanitarian system is self-serving and part of the problem, not the solution (Bradbury et al., 2000).

Seeds-and-tools programmes have been widely implemented throughout southern Sudan as a way of increasing the population's food security (Hines et al., 1999; Macrae et al., 1997). Procedures for assessing seed needs tend to be based on food needs assessment (see Longley et al., this issue). Similarly, the design of approaches to address assumed seed deficits has paralleled responses to food deficits. 
In southern Sudan this has included transporting surplus grain and seeds from Western Equatoria, an area of plentiful rainfall, fertile soils and relative security, to food-deficit — and assumed seed-deficit — areas in other provinces (Fielding et al., 2000). What differentiates the approach used for seeds from that for food was the establishment of three seed projects in Tambura, Yambio and Maridi with the primary objectives of reducing the costs of seed relief assistance and institutionalising the production of quality seeds and seed self-sufficiency within southern Sudan (Salinas and D'Silva, 1999). This approach represented a transition from relief to development that was largely justified if one applies the criteria presented by Maxwell (1999), and was made possible by long-term funding from USAID that was outside of the UN Consolidated Appeal Process that restricts agencies to a short-term project cycle (Hines, 1999).

Based upon fieldwork conducted in Western Equatoria, Bahr-el-Ghazal and Lakes provinces from 2000 to 2001, this paper describes issues relating to seed security in southern Sudan and examines the three local-level seed production projects mentioned above. The major research question was to determine whether the relief seed distribution model of multiplying seed in Western Equatoria for distribution to farmers in Bahr-el-Ghazal and Lakes has addressed the needs of farmers. The paper shows that farmers have well-developed and resilient seed systems and exhibit a strong preference for locally adapted sorghum varieties. As a result, there is almost no effective demand for seed beyond that generated by relief agencies themselves. Based on these findings, a range of alternative interventions is proposed. This research is intended to provoke discussion not only among those concerned with southern Sudan, but among a wider audience as the seemingly never-ending demand for relief seed is affecting the development of agricultural institutions throughout sub-Saharan Africa (Tripp, 2001).

\section{Methodology}

The research reported in this paper is based on information collected by three approaches: a detailed review of agricultural research literature from southern Sudan; a series of informal interviews and focus group discussions with farmers, local leaders and project staff in the field; and a formal household survey. Agricultural research literature was reviewed by Slaymaker (2001a, 2001b) who visited archives in the UK and Norway, and also met with a number of agricultural researchers that had worked in the country before the present conflict and were able to provide documentation from this period. Three field visits were made to southern Sudan; one to Western Equatoria in February 2000, and two to Bahr-el-Ghazal and Lakes in May 2000 and again in late January 2001. The field team was made up of agronomists, a social anthropologist, a genetic resources specialist and local agricultural staff familiar with the cropping systems of the area. During the first field trip to Western Equatoria, staff from three seed projects, in Tambura, Yambio and Maridi counties, were interviewed as well as farmers who had been contracted to grow seed for these projects. The second and third field visits were used to interview individual farmers and hold focus group discussions in Bahr-el-Ghazal and Lakes where much of the seed from the three seed projects in Western Equatoria had been distributed. Finally a formal survey was conducted in June 2001 involving 210 households from 30 villages that were randomly selected from Wulu, Pakot, Pakong and Rumbek Payams in Rumbek County. The purpose of the survey was to determine the level of seed insecurity caused by the 1998 drought, 
and the extent to which emergency and local seed systems had met the demand for seed following that drought.

\section{Background to Western Equatoria, Bahr-el-Ghazal and Lakes provinces}

Since 1997 there has been relative security over much of the three provinces along the west bank of the Nile River: Western Equatoria, Bahr-el-Ghazal and Lakes. These three provinces are contiguous with each other allowing for internal trade, and with Uganda in the south. Insecurity is largely confined to the northern fringes of Bahr-elGhazal and Lakes, and around government-controlled enclaves, especially the town of Wau and the railway corridor to Khartoum in the north. ${ }^{1}$ In Bahr-el-Ghazal and Lakes the disaster is principally civil and chronic, but climatic disasters - primarily drought - from time to time have added an extra degree of complexity. Throughout the south there is a lack of services, households have lost assets and markets have been disrupted. Impacts on household food security have not been homogeneous: severe famines affected much of Bahr-el-Ghazal and Lakes in 1988 and again in 1998 (Fielding et al., 2000), but Western Equatoria was largely unaffected by these events.

Western Equatoria is known for its production of agricultural surpluses, despite the subsistence nature of the crop production system that is based on shifting cultivation. Because it is relatively stable with high agricultural potential, the area has attracted internally displaced people from less-favourable and insecure areas. The high potential of the area is a direct result of plentiful rainfall averaging 1,350 to $1,600 \mathrm{~mm}$ per annum, and fertile soils with the result that own produced crops contribute 85 per cent of household food needs and in good years surpluses of up to 150 per cent have been recorded.

Moving north-east from Western Equatoria to Bahr-el-Ghazal and Lakes provinces, the agro-ecology becomes drier and livestock production and fishing are also undertaken in addition to crop production. Rainfall in these areas is around half that in Western Equatoria. Cropping systems in Bahr-el-Ghazal and Lakes are highly developed to cope with the prevailing agro-ecological environment, which is not very favourable to crop production. Particular problems faced by farmers include sandy soils with low inherent fertility, widespread water-logging during the rainy season because of poor drainage, and hot, humid conditions during the growing season that provide an ideal environment for insect pests and diseases. Farmers solve these problems using crop and varietal diversity, staggered planting dates and crop mixtures. This is particularly evident in the staple cereal: sorghum.

Sorghum is the dominant cereal grown throughout most of southern Sudan, and the country is recognised as having unique diversity in this crop. Traditional sorghums are highly photoperiod sensitive so that the growth and development of the crop is in synchrony with the growing season. However, this close adaptation of the crop to the environment means that these varieties cannot be easily moved in a north/south direction as day-length changes associated with different latitudes makes them poorly adapted to the new environments. Farmers plant early-, medium- and latematuring varieties on the same farm to meet household food requirements throughout the year. Local sorghums are well adapted because they can withstand water-logging, produce grain under marginal fertility conditions, withstand diseases, resist insect pest infestation, withstand the ravages of the parasitic weed Striga that is endemic to many 
areas and produce hard grain that is protected by long glumes ${ }^{2}-$ so it stores well and tastes good. In addition, the long-duration varieties mature at a time when bird attack is reduced because of the abundant grass vegetation in the area that provides an alternative source of food for the birds. Different sorghum varieties are used for different food and drink preparations depending on their grain qualities.

\section{Understanding seed systems: farmer and formal}

Throughout most of Africa the majority of smallholder farmers use their own saved seed for planting. The amount of seed saved is determined by several factors including the size of farm to be planted in the next season, the type of crop and the need for multiple plantings where stand establishment might be affected by drought, pests, diseases or a combination of factors. Seed is not differentiated from grain through the application of established standards but by individual farmers who may select certain plants in the field for harvesting specifically as seed, or by separating grain to be used as seed at some stage after harvest. If farmers do not have own saved seed, a range of acquisition methods are used to acquire seed including begging, purchase, barter or as a loan. Seed can be acquired from several sources including relatives, neighbours, friends or local markets. When seed is acquired from local markets, the quality of seed is determined by the buyer otherwise it tends to be regulated by social norms of reciprocity or 'good neighbourliness'. Farmers, relying on what is sometimes referred to as the farmer seed system (as outlined above), may acquire new varieties by local selection, through social networks, from traders bringing grain into an area from outside and — in the case of southern Sudan — from humanitarian agencies.

In commercial agriculture, farmers routinely purchase seed for planting from commercial seed companies sometimes referred to as the formal seed sector. The choice of seed of different crops and varieties is a commercial decision based on the needs of the market, and what will grow well on that particular farm. Farmers learn about the suitability of different crops and varieties through experience, and from other sources including promotional material from seed companies and independently run trials. Seed produced by the formal seed sector is differentiated from grain by the way in which it is managed from planting through to the point of sale. Countries with a formal seed sector have established standards (enshrined in seed legislation) that must be adhered to if the product is to be marketed as seed rather than grain. These standards are designed to ensure that seed is of acceptable quality in terms of varietal integrity (the plant that grows from the seed should be true to type) and physiology (germination percentage being most commonly used to determine whether the seed is viable or not). Farmers purchase seed in the knowledge that the variety being sold will be true to type and that the seed will germinate. If this is not the case, the farmer can resort to law and obtain compensation. There is a strong incentive for seed companies to understand the needs of end-users - both farmers and markets - environmental constraints to production, and to maintain rigorous quality standards from multiplication through to marketing otherwise their business will fail. The formal seed sector is dependent on agricultural research and development for the supply of new ('improved') varieties developed by plant breeders. 
Table 1 Major source of seed planted by sample farmers in 1999 and 2000 in Rumbek County, Bahr-el-Ghazal ${ }^{3}$

\begin{tabular}{llrlll}
\hline Crop/year $(N)$ & \multicolumn{5}{c}{ Percentage of responses recording source of seed } \\
\hline & $\begin{array}{l}\text { Own } \\
\text { saved } \\
\text { seed }\end{array}$ & Relatives & $\begin{array}{l}\text { Non- } \\
\text { relatives }\end{array}$ & Traders & NGOs \\
& & & & & \\
Sorghum & 76 & 11 & 3 & 3 & 0 \\
$1999(\mathrm{~N}=1,587)$ & 80 & 9 & 3 & 5 & 0 \\
$2000(\mathrm{~N}=1,489)$ & & & & & \\
All crops surveyed & 83 & 8 & 3 & 5 & 2 \\
$1999(\mathrm{~N}=4,263)$ & 79 & 10 & 3 & 6 & 2 \\
$2000(\mathrm{~N}=4,816)$ & & & & &
\end{tabular}

\section{Sorghum seed systems in southern Sudan}

In southern Sudan there is no formal seed sector, and little understanding or appreciation about how farmers traditionally manage seed. It is generally assumed that food shortage translates into seed shortage, which is not surprising as seed is grain that is selected for planting rather than consuming, and many relief seed interventions are justified on this basis. It is important to note that for most crops, the amount of seed required to establish a new crop is only a small fraction of the total harvest. For sorghum, the seed requirement is $5-10 \mathrm{~kg}$ /household compared to an average annual household food requirement of $300 \mathrm{~kg}$ (Fielding et al., 2000). The seed multiplication rate is approximately 100 (ODI Seeds and Biodiversity Programme, 1996). Although locally produced seed can be consumed as grain and vice versa, the same cannot be said for imported grain and seed. Farmers are acutely aware of the risk of crop failure from planting imported grain, and because they are unlikely to know the origin or performance of imported seed, tend to treat it with caution until it has been locally proven.

In May 2001, a survey of 210 randomly selected households in Rumbek County, Bahr-el-Ghazal was taken in which farmers were asked to list where they obtained sources of seed for planting in the 1999 and 2000 seasons (see Table 1). These two years were selected as the 1999 season was preceded by a severe famine in Bahr-el-Ghazal, which resulted in crude mortality of at least 100,000 people and excess mortality of about 70,000 people (Deng, 1999). ${ }^{4}$ It is clear from Table 1 that own saved seed was the most important seed source for both sorghum and all crops surveyed, ${ }^{5}$ even in 1999 following the severe famine. The next most important source was relatives, and then traders.

These data reinforce the resilience of the farmer seed system even under extreme stress, although they do not provide information on whether the amount of seed provided was sufficient to meet the total seed need. In the words of one elderly female farmer who buried her seeds to protect them from being eaten during the famine period 'why would we eat our seeds, when all we would get is one meal, and then we would have nothing to plant?' Although food was short, seed was still available within the community from other people, both relatives and non-relatives, and traders as evidenced in Table 1. In the same survey, households were asked if they were aware of 
Table 2 Farmers' perception of quality and general performance of seed from various sources (includes all crops surveyed in Rumbek County, Bahrel-Ghazal)

\begin{tabular}{|c|c|c|c|}
\hline \multirow[t]{2}{*}{ Source of seed } & \multirow[t]{2}{*}{ Year } & \multicolumn{2}{|c|}{$\begin{array}{l}\text { Percentage of responses reporting satisfaction } \\
\text { with various aspects of seed quality }\end{array}$} \\
\hline & & Germination & General performance \\
\hline \multirow{2}{*}{ Own saved seed } & 1999 & 99 & 87 \\
\hline & 2000 & 91 & 79 \\
\hline \multirow[t]{2}{*}{ Other farmers } & 1999 & 98 & 85 \\
\hline & 2000 & 98 & 83 \\
\hline \multirow[t]{2}{*}{ Traders } & 1999 & 84 & 67 \\
\hline & 2000 & 85 & 60 \\
\hline \multirow{2}{*}{ NGOs } & 1999 & 100 & 91 \\
\hline & 2000 & 97 & 76 \\
\hline
\end{tabular}

Source: ICRISAT/ODI/CRS seed survey, 2001

individuals in the community who had seed, and invariably they named better-off farmers who were able to cultivate and manage larger areas.

\section{The relief seed system: common misperceptions}

In most relief seed deliveries, the seed is obtained from the formal sector. When comparing seed produced in the formal and farmer seed systems, there are a number of common misperceptions that need to be corrected. The first misperception is that farmer saved seed is not of high physiological quality in terms of germination percentage and physical purity when compared to seed from the formal seed sector. Very rarely do farmers complain about the quality of their own saved seed or seed that has been sourced locally (see Table 2). Farmers have well-developed seed storage systems and prefer to plant seed of known origin. It is true that the genetic purity of farmer saved seed can be variable compared to seed from the formal seed system, but farmers growing crops mainly for subsistence perceive genetic purity differently. In commercial agriculture uniformity is important both for mechanised crop husbandry, and to meet grades and quality standards demanded by the market.

The second misperception is that varietal integrity and seed quality deteriorate over time when seed is recycled from season to season. Farmers do not perceive this to be the case, and the fact that crops were first domesticated, and subsequently improved from such practices, suggests that this is patently not true. There are exceptions to every rule, and the farmer seed system cannot maintain varietal integrity of hybrid crops whose seed is produced through specialised procedures. For the crops presently being grown by farmers in southern Sudan, there is little justification to intervene with the farmer seed system on the basis of seed quality or varietal integrity.

The third misperception is that because poor farmers very often do not have own saved seed, there is a problem of seed availability. Such farmers routinely receive seed from other farmers - both relatives and non-relatives - from local traders (Table 1), and through the mechanisms shown in Table 3. Table 3 illustrates the frequency and scale with which seed is provided by better-resourced farmers to those requiring seed. Problems arise for poor farmers when they have weakly developed social 
Table 3 Provision of seed by farmers (including all crops surveyed in Rumbek County, Bahr-el-Ghazal, N=210 farmers)

\begin{tabular}{lcclr}
\hline $\begin{array}{l}\text { Method of seed } \\
\text { provision }\end{array}$ & Year & $\begin{array}{l}\text { Frequency (number of } \\
\text { times seed was provided } \\
\text { by sample farmers) }\end{array}$ & $\begin{array}{l}\text { Amount of seed } \\
\text { provided in } k g\end{array}$ \\
\hline \multirow{3}{*}{ Gift* } & & & Mean & Sum \\
Seed exchange & 1999 & 67 & 7.5 & 500 \\
& 1999 & 98 & 8.1 & 794 \\
Exchange with other & 2000 & 5 & 4.3 & 17 \\
items & 1999 & 20 & 4.3 & 21 \\
Cash sales & 2000 & 22 & 6.3 & 125 \\
& 1999 & 2 & 9.5 & 212 \\
& 2000 & 2 & 6.0 & 12 \\
\hline
\end{tabular}

*Farmers indicating gift, were not asked about whether they gave to more than one farmer

Source: ICRISAT/ODI/CRS seed survey, 2001

networks or few assets that can be exchanged for seed. In such cases, the problem is then one of access not availability.

The two most common justifications for providing relief seed are that there is a problem of seed availability, or farmer saved seed is of poor quality. If we accept these arguments, although neither is usually justified, from where should seed be sourced for provision to affected communities? Usually the first port of call for humanitarian agencies wanting to procure seed is commercial seed companies. In the case of southern Sudan, this has meant sourcing seed from either Kenya or Uganda where there are established seed companies. Decisions on seed procurement are often made on the basis of what seed is available from commercial suppliers. Because the need for seed is not foreseen until after harvest, humanitarian agencies only have a short time frame in which to source and distribute seed before the start of the next rainy season. Very few seed companies are willing to multiply and maintain large inventories of expensive certified seed for a market where there is uncertain demand, with the result that much of the seed supplied is 'conditioned' grain that is sold at seed prices. $^{6}$ As a result of several bad experiences, humanitarian agencies have started to insist that seed is tested for germination percentage, but it is not possible to determine varietal integrity from a physical seed inspection without actually growing out the crop. In one extreme case, an international NGO supplied farmers with seed of shatter cane - a weedy sorghum they thought was grain sorghum seed (Obilana, pers. comm.).

\section{Relief seed production in Western Equatoria}

Starting in the mid-1990s, increasing amounts of relief seed distributed in southern Sudan have been sourced from three projects that were established in the grain surplusproducing areas of Western Equatoria with donor support (Salinas and D'Silva, 1999). The relative stability and agricultural potential of Western Equatoria were major factors in USAID's decision to invest in economic transition to jump-start the market economy, promote the development of civil society and further the creation of a functional, transparent and accountable civil administration (Salinas and D'Silva, 1999). The history of the three projects is relatively complex as they were not 
originally conceived of as seed production projects, but got involved in seed production because the returns were higher than for local grain purchase.

The original objective of the three projects was to stimulate agricultural recovery and enterprise development through local grain purchase in return for barter commodities (Salinas and D'Silva, 1999). Analysis from the World Food Programme Technical Support Unit using the household food economy approach has been used to inform donors of the need to purchase surplus production from Western Equatoria for distribution in food-deficit areas (Fielding et al., 2000). By extending the logic of the household food economy approach from food to seed, the need to purchase seed from Western Equatoria for distribution in areas perceived to be in need of seed was readily accepted both by donors and agencies operating under Operation Lifeline Sudan (OLS). ${ }^{7}$ As a consequence, the success of these grain-purchasing initiatives was very soon extended to supplying seed in addition to grain, in response to demand by OLS agencies for their seeds-and-tools and agricultural programmes (Campbell, 1997). In line with a more developmental approach, there was also the expectation that the production of quality seeds could be institutionalised and seed self-sufficiency in southern Sudan achieved (Salinas and D'Silva, 1999). The three schemes in question were the Tambura County Seed Production and Marketing Programme started in 1999, a similar initiative in Yambio County started in 1997/8 and the Maridi Farmers' Association. The first two projects were implemented by NGOs, while the latter was created in the early 1990 s with support from UNICEF. ${ }^{8}$

All three projects put in place mechanisms to monitor seed production that was primarily of the open-pollinated modern sorghum variety known as Serena. This basically consisted of growing the seed crop in isolation from other sorghums to avoid cross-pollination, and ensuring that the seed was properly conditioned after harvest. Around this time, FAO established a seed laboratory in Lokichoggio, Kenya to verify independently germination percentage and analytical quality of multiplied seed from the three seed projects and other seed suppliers. In the Tambura and Yambio schemes, farmers were paid directly by NGOs, which took responsibility for seed storage. The Maridi Farmers' Association was managed by a locally elected committee, which was responsible for seed transport, storage and negotiating contracts directly with relief agencies.

In summary, the local seed production schemes in Western Equatoria were established for four major reasons:

- The problem of quality that had been experienced with imported commercial seed could be addressed through supervising the seed production process.

- The cost of seed could be reduced and money from seed production would benefit farmers in Western Equatoria desperately in need of markets for surplus production.

- Locally produced seed was thought to be more appropriate than imported seed in terms of adaptation.

- Investment in such schemes would strengthen and support local seed production capacity that could potentially lead to the establishment of a formal seed sector in southern Sudan. 


\section{Impact of the relief seed schemes}

Undoubtedly the major impact of the three seed schemes has been to inject cash into the local economies of the areas where they operate. Although the quality of seed produced by the schemes has been somewhat variable, it is not easy to determine whether this has been because of poor management by the seed schemes or problems that have occurred once the seed has been collected by humanitarian agencies.

\section{Lack of local capacity and limited seed markets}

Similar seed production projects implemented as development interventions in different countries have been reviewed by Tripp (2001). Some such projects have not been sustainable, and others have successfully built up local capacity. One of the main failures of such projects has been the inability to realise that the seed provision process includes more than seed multiplication: agencies implementing the projects have tended to manage the contacts (and cover the transaction costs) involved in obtaining source seed, establishing quality-control procedures, arranging for seed conditioning and marketing the produce (Tripp, 2001). Failures to address marketing issues have been particularly significant, and in many cases there is insufficient demand for offfarm seed to allow such small-scale seed enterprises to exist as viable operations.

A visit made to Western Equatoria just after two NGOs had been forced to withdraw support to two of the seed schemes ${ }^{10}$ starkly illustrated these deficiencies; without the presence of the NGOs, contract farmers were unable to sell their seed surpluses. The only market for seed was that provided by relief agencies. In the case of the third seed scheme, the capacity of the farmers' association was much better developed, and it was able to continue to supply seed for the relief market. The relief seed system is based upon the assumption that farmers have a continual need for seed because of the failure of the local, farmer seed system to operate under the chronic disaster conditions. The resilience of farmer seed systems, however, has been illustrated above.

\section{Choice of crop varieties}

The major problem with the schemes concerns the choice of crops and varieties, and the assumption that because the seeds were being grown within southern Sudan they were 'local' and hence adapted. Although Western Equatoria might be considered 'local' to Bahr-el-Ghazal in terms of political boundaries, the two areas have different agro-ecologies and different ethnic groups. From the seed perspective, a variety can be considered 'local' when many farmers have adopted the variety within a specific agroecology, thus indicating that it is appropriate to the particular farming system in which it is to be used.

The three seed schemes in Western Equatoria multiplied Serena sorghum; this is a non-photoperiod-sensitive variety that matures in three and a half months and was developed in Uganda in the early 1960s. The variety was developed specifically as an early maturing commercial crop that could be harvested before the main crops were ready. However, because birds are a major problem at this time, the variety was developed with high tannin content to reduce the incidence of bird damage; this high tannin content also gives Serena a slightly bitter taste. Despite repeated distributions of 
relief seed of this variety to farmers in southern Sudan, they have largely continued to plant seed of their own preferred local varieties.

\section{The inappropriateness of a formal seed sector in southern Sudan}

The existence of a relief seed market has underpinned the operations of the three seed schemes in Western Equatoria. Without a commercial farming sector the conditions for the development of a formal seed sector do not exist. There is no commercial farming sector in southern Sudan, and even in countries such as the US where there is commercial agriculture, seed companies have found it hard to multiply and market seeds of non-hybrid food crops. Apart from hybrids, the formal seed sector only finds it profitable to market seeds of vegetables and some cash crops such as cotton and sunflower.

\section{Lessons from previous agricultural development}

One of the consequences of war is the loss of human capacity and institutional memory that occurs which is particularly the case for agricultural research. A detailed review of agricultural research in southern Sudan post-1945 (Slaymaker, 2001a, 2001b) found several references to the fact that imported varieties of traditional crops indigenous to the area were either inferior to or no better than local varieties. Bennett (1979) had already discovered the superiority of local sorghum germplasm over dwarf quickmaturing types. The fact that three seed multiplication schemes multiplied seed of a variety that was known to be inferior to local germplasm as far back as 1979 underscores the need for humanitarian agencies to draw upon all available information before embarking upon humanitarian interventions, especially when these are repeated from season to season and little attempt is made to determine the impact from previous interventions. In making the transition from relief to development, Maxwell (1999) makes the point that emergency and development capacities should be incorporated into the same core staff not only to ensure a more rapid and professional response to emergencies that may develop quickly, but also to 'demystify' the emergency response. It is worth stressing that the seed sector in sub-Saharan Africa — even without the added complexities of chronic political instability — is not well developed, and that considerable investments have been made in community seed-production projects that have not been sustained beyond the life of the project (Tripp, 2001).

\section{Alternative interventions}

If we accept the hypothesis that there is no absolute lack of seed and that farmer seed is not of poor quality, how can we facilitate access to seed by people who have difficulty saving their own seed or getting hold of seed for reasons of poverty in the wider sense? When there is a poor harvest or widespread displacement of people because of war, the provision of food reduces the pressure to consume stocks of own saved seed, and also provides an asset that can be used by poor people to barter for seed. The provision of seed alone in such situations will have minimal impact. Even if the seed is consumed, the impact on household food security will be minimal, as the quantities of seed that are distributed would only meet a small fraction of the total household food 
requirements. To be effective, relief seed distribution must be of adapted crops for which farmers have a problem accessing seed. The broad bio-diversity within and between crops underlies the strength of the cropping system, and any relief seed intervention must therefore take this into account. The best source of seed of adapted varieties in such situations is the farmer seed system itself. Indeed, many seeds-andtools projects now procure seed from within the very same communities where it is to be distributed. But is such procurement and redistribution really necessary? One approach that has been used to address this issue is the use of seed vouchers and seed fairs, and is the subject of a paper by Remington et al. (2002) elsewhere in this issue.

\section{Promoting resilience through varietal diversity}

A weakness of the farmer seed system in areas such as southern Sudan is the absence of any effective mechanism to link the farmer seed system to sources of new germplasm that would normally come from research, trade networks and the formal seed sector. This provides an opportunity for relief agencies to inject small quantities of seed that would permit farmers to test and experiment with new crops and varieties. Unfortunately the short planning time frame under which agencies operate in disaster situations, and the lack of any historical perspective related to agricultural interventions in southern Sudan has largely resulted in a missed opportunity. Where unknown seed has been introduced, farmers have shown their willingness to test and experiment with the new varieties. A good number of farmers now grow 'UN' okra alongside their traditional variety, and there has been widespread adoption of improved groundnut varieties into the system both during the colonial era (the variety 'Mr Lake', named after the colonial officer who first introduced the variety, is almost universally grown and can be considered 'local'), and more recently with the introduction of the variety Red Beauty from Uganda. The fact that this has not happened with Serena sorghum should have been noticed and acted upon. Draught-animal technologies are also gaining greater acceptance, and are being actively promoted by several agencies. These examples show that cropping systems are dynamic, and that farmers are willing to try out new technologies, but the process cannot be forced through continued injections of varieties that farmers do not find acceptable.

Small seed injections of the type described above might not be considered for funding in disaster situations, but the strengthening of the local cropping systems is an intervention that very much fits into the area of disaster preparedness. The lack of institutional memory in disaster situations such as in southern Sudan is largely the result of crisis management with rapid staff turnover and little investment in human capacity to address the underlying causes of poverty in such areas. A more developmental approach based on a better understanding of livelihoods and farming systems could potentially help agencies to build human capacity that is capable of switching from development to relief as and when the situation arises, rather than the present situation of focusing only on relief.

\section{Conclusions}

The complexity of local farming systems makes it extremely hard for outside agencies to provide appropriate seed, and repeated interventions run the risk of undermining 
local institutions and creating dependency on outside agencies. In complex longrunning emergencies as in southern Sudan, there is an urgent need for more thought-out seed-based interventions that can help farmers cope with adversity.

In the area of crop and varietal choice, rather than imposing outside solutions through repeated free seed distributions, greater attention needs to be given to understanding the strengths and weaknesses of existing seed systems, and then designing interventions to address the identified weaknesses. A major bottleneck faced by farmers is that of accessing new crops and varieties that are potentially suitable both to the needs of farmers and markets, and that might be available from similar agroecologies or have been developed by research. The process of experimentation by farmers needs to be encouraged and evaluated rather than the more conventional approach where varieties are screened and tested for several seasons under controlled conditions before farmers are involved. It is difficult to achieve the latter objective in disaster situations where there is lack of infrastructure and technical capacity, but it is relatively straightforward to carry out the former — a process that occurs without outside intervention. Germplasm-based solutions are not a panacea, and there is a need to look beyond just seeds and tools. Farmers in southern Sudan are faced with a lack of marketing opportunities, and this can be made worse by repeated free food distributions that result in artificially low market prices. Creation of artificial markets that are based on relief needs, as was the case with the seed multiplication schemes in Western Equatoria, is not sustainable in the long term.

Both relief and development interventions in the field of agriculture should avoid a paternalistic top-down approach but need first to understand and then strengthen existing institutional arrangements. Seed interventions throughout Africa in both disaster and non-disaster situations have largely failed because there has been a tendency to assume that modern technology and formal systems are best, and that there is little value in strengthening what already works. A more business-like approach where the farmer is treated as a potential client rather than the more common and unsustainable supply-side interventions is likely to have greater impact.

\section{Acknowledgements}

The financial support of the US Agency for International Development, Bureau for Humanitarian Response, Office of Foreign Disaster Assistance that supported this research is gratefully acknowledged.

\section{Notes}

1. As this is an ongoing conflict the security situation can change at any time.

2. Outer cover of leaf-like material.

3. Although farmers regularly acquire seed from multiple sources, this table presents the farmers' main source for each crop type in a specific planting season.

4. Crude mortality reports the total number of deaths (from whatever cause), whereas excess mortality reports the number of deaths considered to be above the 'normal' death rate.

5. In addition to sorghum, other crops included in the survey were: pearl millet, groundnuts, sesame, okra and pumpkins.

6. In defence of reputable seed companies, some relief agencies opt for 'conditioned' grain that is competitively priced relative to certified seed. This is especially true when there is no seed legislation in the destination country prohibiting such practices. 
7. Operation Lifeline Sudan was established in 1989 in the wake of war-induced displacement and famine in Bahr-el-Ghazal and allowed for the provision of assistance to war-affected populations on all sides.

8. Work in Tambura and Yambio counties had been undertaken by the same NGOs prior to these dates, but seed production only started later. UNICEF withdrew support to the Maridi Farmers' Association in 1995, after which the association remained active with some donor support. Salinas and D'Silva (1999) provide a comprehensive review of these projects.

9. Seed quality within farmer seed systems is controlled by social norms of reciprocity, whereas in the formal sector seed schemes, seed is produced commercially; without seed regulation, the onus is on the producer (i.e. the project) to maintain quality standards.

10. This withdrawal was not planned but came about following the Memorandum of Understanding issued by the SPLM concerning NGO operations in southern Sudan (see Anon., 2000).

\section{References}

Anon. (2000) Humanitarianism: Imperatives and Principles in Southern Sudan. Newsletter 16, Relief and Rehabilitation Network, Overseas Development Institute, London.

Bennett, A.J. (1979) Completion Report and Handing Over Notes. Project Development Unit (PDU), Regional Ministry of Agriculture, Agronomy Section-Yei. Mimeo.

Bradbury, M., N. Leader and K. Mackintosh (2000) The 'Agreement on Ground Rules' in South Sudan. Humanitarian Policy Group, Overseas Development Institute, London.

Campbell, W. (1997) CARE, Rehabilitation and Greater Horn Project: Rehabilitation in South Sudan. Institute of Development Studies, Brighton.

Carney, D. (1998) Implementing the Sustainable Rural Livelihoods Approach. In D. Carney (ed.) Sustainable Rural Livelihoods: What Contribution Can We Make? DFID, London.

Deng, L.B. (1999) Famine in the Sudan: Causes, Preparedness and Response. A Political Social and Economic Analysis of the 1998 Bahr-el-Ghazal Famine. Discussion Paper 369, Institute of Development Studies, Brighton.

Fielding, W., C. Gullick, P. Coutts and B. Sharp (2000) An Introduction to Food Economy Research in Southern Sudan 1994-2000. World Food Programme/Save the Children (UK), Technical Support Unit, Loki, Nairobi.

Hines, D. S Wickrema and L. Van Straaten (1999) Food and Seed Assistance in the Recovery from Crisis. In Restoring Farmers' Seed Systems in Disaster Situations. Plant Production and Protection Paper 150, FAO, Rome.

Longley, C., C. Dominguez, M.A. Saide and W.J. Leonardo (2002) Do Farmers Need Relief Seed? A Methodology for Assessing Seed Systems. Disasters 26(4): 343-55.

Macrae, J., M. Bradbury, S. Jaspars, D. Johnson and M. Duffield (1997) Conflict, the Continuum and Chronic Emergencies: A Critical Analysis of the Scope for Linking Relief, Rehabilitation and Development Planning in Sudan. Disasters 21(3): 223-43.

Obilana, A.B. (2002) Personal communication from Kenya.

ODI Seeds and Biodiversity Programme (1996) Seed Provision During and After Emergencies. Good Practice Review 4, Relief and Rehabilitation Network, Overseas Development Institute, London.

Remington, T. (2001) Guidelines for Assessing the Impact of Disaster on Smallholder Agricultural Systems. In L. Sperling (ed.) Targeted Seed Aid and Seed-system Interventions: Strengthening Small-Farmer Seed Systems in East and Central Africa. CIAT, Kampala.

_ J. Maroko, S. Walsh, P. Omanga and E. Charles (2002) Getting Off the Seeds-and-tools Treadmill with CRS Seed Vouchers and Fairs. Disasters 26(4): 316-28.

Salinas, A.O. and B.C. D'Silva (1999) Evolution of a Transition Strategy and Lessons Learned: USAID-funded Activities in the West Bank of Southern Sudan, 1993 to 1999. Regional Economic Development Services Office, East and Southern Africa, Nairobi.

Slaymaker, T. (2001a) Literature Review of Agricultural Research Conducted in Southern Sudan Post-1945. Consultancy report for ICRISAT/CRS/ODI Seed Study, Nairobi. 
(2001b) Review of Norwegian Literature on Agricultural Research in Southern Sudan. Consultancy report for ICRISAT/CRS/ODI Seed study, Nairobi.

Tripp, R. (2001) Seed Provision and Agricultural Development. James Currey, Oxford.

Address for correspondence: Richard B. Jones, ICRISAT-Nairobi, PO Box 39063, Nairobi 00623, Kenya. E-mail: «r.jones@cgiar.org» 